\title{
Research and analysis of selected LED lamps with E27 base in the field of harmonic distortion
}

\author{
Lukasz Putz ${ }^{1, *}$, and Ryszard Nawrowski ${ }^{1}$ \\ ${ }^{1}$ Poznan University of Technology, Institute of Electrical Engineering and Electronics, 60-965 Poznan, 3A Piotrowo Street, Poland
}

\begin{abstract}
The article presents the results of testing of three compact LED lamps with the E27 base. Power quality parameters were subject to the testing in the circuit which powered the LED light sources. Particular attention was paid to higher harmonics of current and the total harmonic distortion. Risks which could follow from the application of the great number of electroluminescent light sources were discussed. The research have been conducted. Then, the obtained testing results for the respective LED lamps were analyzed in comparison with the requirements of the IEC 61000-3-2:2014-10 Standard [1].
\end{abstract}

\section{Introduction}

Lamps with electroluminescent diodes are the latest generation of electric light sources which are introduced into the lighting industry on a large scale. LED lamps replace traditional incandescent lamps, fluorescent lamps and metal halide lamps in the domestic lighting, and also in public utility places [2-4]. Soon these lamps may constitute the great majority among all the electric light sources. At the same time, the risk resulting from the higher harmonics of current generated by LED lamps increases significantly. Semi-conductor light sources of better and better quality are introduced into the lighting market $[5,6]$. However, these are quite expensive solutions, therefore they are used quite reluctantly. Those from the cheapest price segment and with the low quality parameters are selected most frequently. The variation of generation the higher harmonics of current by the LED lamps is extremely large.

\section{Threats arising of LED lamp use}

The LED light sources are capacitive loads and they draw current whose signal is significantly distorted from the sinusoid. Drivers, which are built using DC-DC switched-mode converters, have a significant impact on the character of the LED lamp and the shape of current waveform. As a consequence of this, the power factor declines, the high reactive power is drawn and also higher harmonics of current are generated, which affect voltage distortion in the mains. An increased content of voltage or current harmonics may lead to the improper operation, higher failure rate and even damage to other devices connected to the electrical installations [7-9].

\section{Characteristic of the research subject}

Three types of compact LED lamps with the E27 base were selected randomly for the purpose of conducting the tests. The selected light sources differ from each other in many aspects. The differences result, among other things, from:

- active power of the LED lamp - from 8 to $12 \mathrm{~W}$,

- topology of the driver circuit - buck or boost,

- type of the LED module - SMD, COB or $C O G$,

- colour temperature - from 2700 to $6500 \mathrm{~K}$,

- market price - from 2 to $10 €$.

Parameters of selected light sources are listed in Table 1.

Table 1. Catalogue parameters of the LED lamps with E27 screw base selected to the research [10-12].

\begin{tabular}{|l|c|c|c|}
\hline \multicolumn{1}{|c|}{ Parameter } & LED lamp 1 & LED lamp 2 & LED lamp 3 \\
\hline Active power $P_{n}$ & 12 & 10 & 8 \\
\hline Nominal voltage $U$ & $100 \div 240 \mathrm{~V}$ & $220 \div 240 \mathrm{~V}$ & $220 \div 240 \mathrm{~V}$ \\
\hline Frequency $f$ & $50-60 \mathrm{~Hz}$ & $50 / 60 \mathrm{~Hz}$ & $50 / 60 \mathrm{~Hz}$ \\
\hline Luminous flux $\Phi$ & $1000 \mathrm{~lm}$ & $810 \mathrm{~lm}$ & $1055 \mathrm{~lm}$ \\
\hline Light colour $T_{C}$ & $6500 \mathrm{~K}$ & $2700 \mathrm{~K}$ & $4000 \mathrm{~K}$ \\
\hline Type of $L E D$ & $C O B$ & $S M D 3030$ & $C O G$ \\
\hline No. of $L E D$ Module & 1 & 13 & 6 \\
\hline Driver Topology & buck & boost & buck \\
\hline Price & $2 €$ & $10 €$ & $7 €$ \\
\hline
\end{tabular}

\section{Results of the power quality research}

\subsection{Conclusions of 12 W LED lamp}

The tested power supply integrated in the LED light source is a low-budget circuit without advanced solutions that attenuate the propagation of higher harmonics of current or correct the power factor. This is reflected in the value of current crest factor $C F I$, which is equal to 4.52 and power factor $P F$, which amounts to 0.47 . The driver circuit generates higher harmonics of

\footnotetext{
Corresponding author: lukasz.putz@put.poznan.pl
} 
current with values which significantly exceed the levels permitted in the Standard [1], and this also translates into a very high value of $T H D_{I}$, which amounts to $148.2 \%$.

Odd harmonics are predominant in the spectral graph of current harmonics (Fig. 1); their value, even up to the 25th order, is higher than $1 \mathrm{~mA}$ per each Watt of active power of the LED lamp. The power quality parameters in the system which powers the tested compact LED lamp may deteriorate when many light sources of this type are applied at the same time. Power factor $\cos \varphi$ amounts to 0.95 and were it not for pretty low component values $h 3$ and $h 5 \quad(86.8 \%$ and $64.2 \%$ respectively), the tested LED lamp would demonstrate compliance with requirement of the Standard [1].

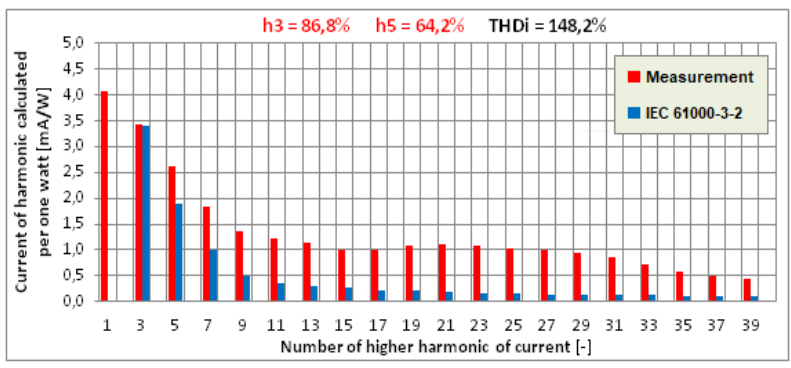

Fig. 1. Harmonic spectrum of current in 12 W LED lamp.

\subsection{Conclusions of $10 \mathrm{~W}$ LED lamp}

The electrical parameters of the power supply circuit integrated in the tested LED lamp prove its high class. The crest factor of the current waveform $C F I$ was 1.74 and approximates the crest factor of the sinusoidal signal $\left(C F I_{\text {sin }}=1.41\right)$, which translates into the lower content of higher harmonics in the current waveform (Fig. 2).

Furthermore, also high and comparable values of both power factors $(\cos \varphi=0.94$ and $P F=0.91)$ were obtained. Therefore, a filter for attenuation of the higher harmonics of current was applied in the driver (PFC circuit). Owing to this, the tested light source meets all requirements of the Standard [1]. The provision of the LED driver based on the boost converter allowed much smaller current distortions to be obtained than in the case of buck converters. This is reflected, for instance, in the low (by the standards of compact LED lamps) value of $T H D_{I}$ which is $24.5 \%$.

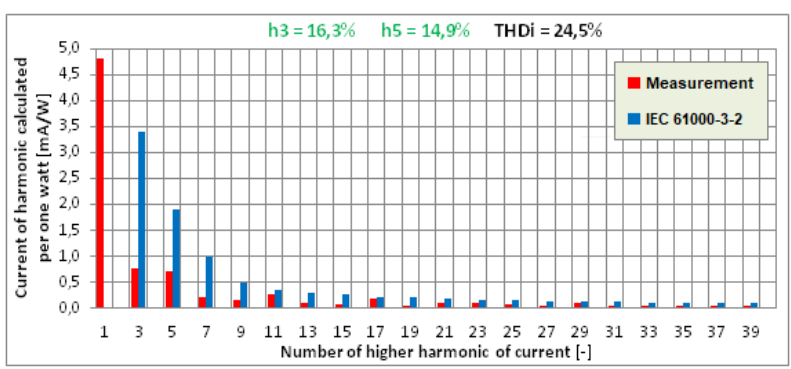

Fig. 2. Harmonic spectrum of current in 10 W LED lamp.

\subsection{Conclusions of $8 \mathrm{~W}$ LED lamp}

The electrical parameters of the power supply circuit integrated in the tested LED lamp prove its good quality.
The crest factor of the current waveform $C F I$ is 2.03 and deviates from the crest factor of the sinusoidal signal, which means that higher harmonics are present in the current waveform - the total harmonic distortion of current $T H D_{I}$ reaches the level of $51.4 \%$ (Fig. 3). Despite this, the LED meets the requirements of the Standard [1].

The driver circuit was integrated into the power factor correction circuit PFC. This also allowed the high and comparable values of both power factors to be obtained $(\cos \varphi=0.93$ and $P F=0.88)$, though the capacitive reactive power $(Q=3.7$ var $)$ is still high, in reference to the active power $(P=9.5 \mathrm{~W})$.

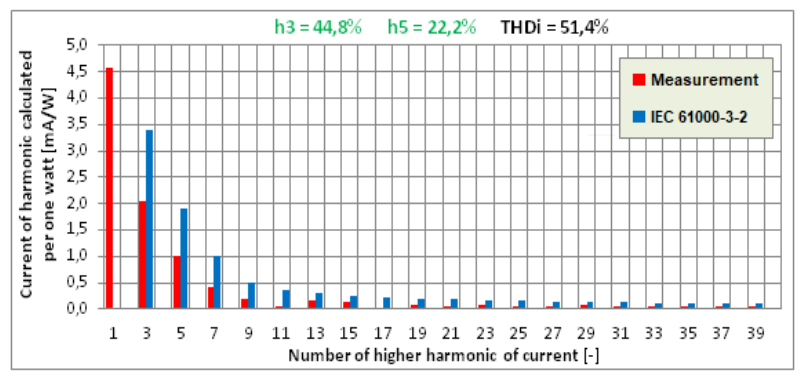

Fig. 3. Harmonic spectrum of current in 8 W LED lamp.

\section{Summary}

The research shows that some of the LED lamps do not exceed limits given in the Standard [1]. These lamps are definitely more expensive than others, and it can be assumed that the manufacturer has made every effort to ensure that his products are compatible with every regulations. However, it can still be a problem for electricity consumers. Among the tested LED lamps, the best in terms of the $T H D_{I}$ achieves $24.5 \%$ and the next one $51.4 \%$. The measurement results of both LED light sources are in accordance with the guidelines of the Standard [1]. After all, these values are too high to strongly conclude that this type of lighting is safety to electrical installations and connected receivers.

\section{References}

1. IEC 61000-3-2:2014-10

2. K. Bednarek, D. Typańska, Prz. Elektrotechniczny, 93, 63-66 (2017)

3. R. Nawrowski, Ł. Putz, Prz. Elektrotechniczny, 89, 296-298 (2013)

4. K. Bednarek, Prz. Elektrotechniczny, 90, 188-191 (2014)

5. Ł. Putz, D. Typańska, Prz. Elektrotechniczny, 90, 111-114 (2014)

6. K. Bednarek, A. Bugała, L. Kasprzyk, D. Typańska, E3S Web of Conferences, EKO-DOK'2018, 44, 00010 (2018)

7. K. Bednarek, L. Kasprzyk, Prz. Elektrotechniczny, 88, 236-239 (2012)

8. M. Kurzawa, Ł. Putz, IEEE Xplore, CPEE'2016, 16450518 (2016)

9. L. Kasprzyk, Prz. Elektrotechniczny, 88, 131-133 (2012)

10. Datasheet of $12 \mathrm{~W}$ COB LED Lamp

11. Datasheet of $10 \mathrm{~W}$ SMD3030 LED Lamp

12. Datasheet of $8 \mathrm{~W}$ COG LED Lamp 